\title{
RÍTMICA E DANÇA NOS CURRÍCULOS DOS CURSOS DE EDUCAÇÃO FíSICA
}

\author{
Daniela Cristina de Amorim \\ Universidade do Estado de Santa Catarina, Florianópolis, Santa Catarina, Brasil \\ Adriana Coutinho de Azevedo Guimarães \\ Universidade do Estado de Santa Catarina, Florianópolis, Santa Catarina, Brasil
}

\author{
Amanda Soares \\ Faculdade Porto das Águas, Porto Belo, Santa Catarina, Brasil \\ Zenite Machado \\ Universidade do Estado de Santa Catarina, Florianópolis, Santa Catarina, Brasil
}

\begin{abstract}
Resumo
Objetivo: Este estudo investigou a disciplina de rítmica e/ou dança nos cursos de Educação Física em Santa Catarina na percepção dos alunos. Metodologia: Amostra do tipo probabilística estratificada aleatória com 387 alunos. Resultados: Os resultados, estatisticamente significantes, foram em relação à importância da disciplina $(\mathrm{p}=0,001)$, dos assuntos abordados $(\mathrm{p}=0,047)$, da disciplina nas aulas de Educação Física $(\mathrm{p}=0,001)$, o conteúdo ritmo desenvolvido nas disciplinas de rítmica e/ou dança $(\mathrm{p}=0,019)$, a utilização de atividade rítmica nas aulas de Educação Física $(p=0,036)$ e no treinamento desportivo $(p=0,001)$. Conclusão: A disciplina tem um objetivo bem definido de não formar bailarinos, e sim professores capazes de atuar em Educação Física Escolar com rítmica e/ou dança.
\end{abstract}

Palavras-chave: Dança. Atividade Física. Ritmo.

\section{Introdução}

Educação Física (EF) é uma área ligada ao movimento humano dança e as atividades físicas em geral. Sendo esta área constituída de práticas corporais que atualmente também são denominadas por alguns autores (BETTI, 1991; DAOLIO, 1996; BRACHT, 2005) como cultura física, do movimento ou corporal. Desta forma o professor de EF tem o corpo como seu objeto de intervenção sendo o principal referencial a ser considerado no seu trabalho e na ação com o aluno (GONÇALVEZ \& AZEVEDO, 2008). Todavia, o contexto vivido durante a formação acadêmica muitas vezes acaba por ter seu foco de interesse unicamente voltado ao âmbito escolar, direcionando os alunos 
para uma experiência corporal intrínseca especialmente voltada para o esporte, não sendo instigada a curiosidade em relação à problematização de uma visão de corpo, além do físico ou do rendimento (PEDRO, 2009).

Ao longo dos tempos, os cursos de EF no Brasil ampliaram sua área de atuação profissional para a dança e o lazer/recreação, pois estas modalidades também desenvolvem atividades motoras comuns ao esporte (VERENGUER, 1997). Esta inclusão permitiu maiores discussões sobre este tema, demonstrando a importância do ensino rítmico junto às ações motoras como recurso preventivo, terapêutico e educativo no caminho para um desenvolvimento integral (CAUDURU, 1989).

A dança, como uma forma de expressão do movimento e cultura corporal, é uma das manifestações mais importantes, encontrando-se entre as atividades propostas nos Parâmetros Curriculares Nacionais de Educação Física (BRASIL, 1997). Merecem atenção especial os conteúdos: dança, ritmo e rítmica, que são os mais presentes. A dança, neste contexto, tem sentido e significado, sendo atribuídas possibilidades de movimentos, reconhecimento de uma linguagem própria e expressiva que conta e representa a história da humanidade através de códigos universais (BRASILEIRO, 2002). O ritmo pode ser igualado a qualquer outra qualidade física, pois está presente em todo o ser, impulsionando-o e estimulando-o para o próprio movimento, enquanto que a rítmica contribui para o estudo da relação ritmo-movimento (SOUZA JR., 2002) por meio das atividades rítmicas, ou seja, práticas lúdicas que possibilitam a criação de um ambiente desafiador no qual o aluno poderá ampliar seu universo estimulando sua coordenação, flexibilidade, concentração, postura, despertando a criatividade, a expressão corporal, a percepção auditiva e a visual (RETONDAR, 2001).

Mesmo percebendo a importância de se preparar melhor o profissional de EF para atuar com o ritmo e/ou a dança, os estudos ou as análises que são realizadas sobre os currículos não apresentam a visão dos acadêmicos e tão pouco sua opinião de como são trabalhados estes conteúdos dentro das instituições de ensino. Fundamentando este estudo nesta preocupação, apresenta-se um novo olhar sobre esta temática com ênfase na análise da proposta metodológica da disciplina de Rítmica nos cursos das instituições de ensino superior (SOUZA JR, 2002), mostrando os benefícios do ritmo nas aulas de EF dentro do de- 
senvolvimento infantil (MULLER \& TAFNER, 2007; BORGES; SOUZA \& PEREIRA, 2008), caracterizando o conteúdo da disciplina de rítmica e sua relação com a formação do profissional em EF (QUEIRÓS, 2003), considerando também a percepção dos alunos das instituições de ensino superior no Estado de Santa Catarina (SC).

\section{Método}

Este estudo de corte transversal foi aprovado pelo Comitê de Ética em Pesquisa com Seres Humanos CEFID-UDESC, protocolo $\mathrm{n}^{\circ}$ 145/2008. Participaram do mesmo 21 instituições de Ensino Superior (IES) com 28 cursos de EF em Santa Catarina, sendo que 24 ofereciam a disciplina de Rítmica e/ou Dança em sua matriz curricular.

A população era composta por 1.181 alunos que cursaram a referida disciplina, tendo sido realizado dimensionamento amostral (BARBETTA, 2004), admitindo-se um erro $\leq 5 \%$, sendo a amostra do tipo probabilística estratificada aleatória, formada por 16 centros. Um sorteio foi realizado nos 5 centros da UNOESC (Joaçaba, Xanxerê, Videira, Chapecó e São Miguel do Oeste) e nos 4 da UNC (Concórdia, Mafra, Curitibanos, Xanxerê e Videira) para escolha de um centro de cada unidade. As turmas foram separadas de acordo com as instituições de ensino a que pertenciam para garantir a representatividade dos centros envolvidos, e realizou-se um sorteio para que sete alunos de cada turma participassem. O tamanho amostral mínimo ficou em 299 alunos e foram coletados os dados de 387 alunos com média de idade de 22,68 +4,59 anos, sendo a amostra representativa da população em questão. Houve a recusa de dois centros em participar do estudo.

$\mathrm{O}$ instrumento utilizado foi composto por um questionário auto aplicável formado de 4 partes: a) características pessoais; b) caracterização da disciplina; c) aplicabilidade no mercado de trabalho; e d) pontos positivos, pontos negativos e sugestões em relação à disciplina. $\mathrm{O}$ instrumento passou pelo processo de validação e clareza (MELO, 2000), tendo sido encaminhado a cinco professores (doutores e mestres) e cinco acadêmicos do curso, escolhidos aleatoriamente. No item clareza as questões que obtiveram notas de 1 a 4 (confusas) foram totalmente alteradas/excluídas do questionário final, as que obtiveram notas de 5 a 7 (pouco claras) foram reformuladas tornando-se mais claras, e as que obtiveram notas de 8 a 10 (clara) foram mantidas. Obteve-se um índice de clareza de 0,97 . Para a validação, seguiu-se a 
mesma lógica, substituindo os itens para inválidas, pouco válidas e válidas, obtendo-se um índice de 0,90 . Com relação à caracterização das disciplinas de acordo com as ementas, os dados foram coletados junto aos coordenadores de cada curso.

O instrumento foi enviado via agência postal para as instituições mais distantes e aplicado pessoalmente nas instituições próximas a capital do Estado. Todos os participantes assinaram o Termo de Consentimento Livre e Esclarecido. Como critério de exclusão foi relacionado à falta de interesse e contato dos acadêmicos ou, os que se recusaram a responder o instrumento, além das instituições que devolveram os mesmos de forma incorreta.

Para análise dos dados utilizou-se pacote estatístico SPSS versão 17.0, aplicando estatística descritiva e inferencial. Admitindo-se um nível de significância 95\%. As variáveis passaram pelo teste ShapiroWilk e o teste Qui-quadrado para a associação entre variáveis independentes (BARROS \& REIS, 2003).

\section{Resultados}

A idade mínima dos acadêmicos participantes foi de 17 e a máxima de 44 anos, embora a maioria deles estivesse entre 19 e 25 anos, sendo em maior parte solteiros $(84,5 \%)$, prevalecendo o gênero feminino $(54,8 \%)$.

As ementas foram utilizadas para descrever as disciplinas escolhendo-se palavras-chave de acordo com as mesmas (tabela 1). Conforme as disciplinas envolvidas, a primeira observação é a de que as nomenclaturas diferem de um curso (IES) para outro, embora as ementas sejam bastante parecidas. 


\begin{tabular}{c|cccccccc}
\hline \multicolumn{8}{c|}{ Palavras Chaves das Ementas } & \\
\hline Ementas & $\begin{array}{c}\text { Afividades } \\
\text { Rítmicas }\end{array}$ & Ritmo & Música & Dança & Coreografia & $\begin{array}{c}\text { Dança } \\
\text { Educaça }\end{array}$ & Foldore & $\begin{array}{c}\text { Expressão } \\
\text { Corporal }\end{array}$ \\
\hline 24 & 7 & 11 & 9 & 18 & 13 & 15 & 11 & 9 \\
\hline
\end{tabular}

Quadro1: Termos relacionados às disciplinas nas ementas das IES

Quando os alunos foram questionados sobre a importância da disciplina para o curso na tabela 2 , a maioria respondeu positivamente, sendo este resultado significativo $(\mathrm{p}=0,001)$. O mesmo aconteceu com a importância dos assuntos abordados em aula $(p=0,047)$ e a importância dessa disciplina nas aulas de EF escolar $(p=0,001)$. Outro tema questionado aos alunos foi a percepção dos mesmos sobre o trabalho do professor, no qual 78,8\% acham que os docentes aconselham bibliografias adequadas para as pesquisas teóricas e 95,9\% concordam que estes possuem preparação cientifica adequada.

Tabela 1: Importância da disciplina relacionada na ementa na visão dos alunos

\begin{tabular}{|c|c|c|c|c|c|c|c|}
\hline & \multicolumn{2}{|c|}{ Feminino } & \multicolumn{2}{|c|}{ Masculino } & \multicolumn{2}{|c|}{ Total } & \multirow[t]{2}{*}{ Valor dep } \\
\hline Importância da disciplina & $\mathrm{N}$ & $\%$ & $\mathrm{n}$ & $\%$ & $\mathrm{n}$ & $\%$ & \\
\hline Sim & 203 & 95,8 & 149 & 85,1 & 352 & 91,0 & $0,001 *$ \\
\hline Não & 9 & 4,2 & 26 & 14,9 & 35 & 9,0 & \\
\hline \multicolumn{8}{|l|}{ Relação teoria X prática } \\
\hline Sim & 197 & 92,9 & 161 & 92,0 & 358 & 92,5 & 0.731 \\
\hline Não & 15 & 7,1 & 14 & 8,0 & 29 & 7,5 & \\
\hline \multicolumn{8}{|l|}{ Importância de assuntos abordados } \\
\hline Sim & 196 & 92,5 & 151 & 86,3 & 347 & 89,7 & $0,047^{*}$ \\
\hline Não & 16 & 7,5 & 24 & 13,7 & 40 & 10,3 & \\
\hline $\begin{array}{l}\text { Importância da disciplina nas aulas de } \\
\text { EF }\end{array}$ & 203 & 95,8 & 149 & 85,1 & 352 & 91,0 & \\
\hline $\begin{array}{l}\text { Sim } \\
\text { Não }\end{array}$ & 9 & 4,2 & 26 & 14,9 & 35 & 9,0 & $0,001^{*}$ \\
\hline
\end{tabular}

* significativo a $95 \%$.

$\mathrm{Na}$ tabela 3 apresentam-se os resultados relacionados à disciplina de rítmica e/ou dança e seus vários conteúdos trabalhados em sala de aula. De acordo com os alunos, os conteúdos relacionados ao movimento são maioria, seguido pelo tema dança e ritmo. É interessante observar que a dança também foi um dos temas mais presentes nas ementas das disciplinas e o ritmo o mais presente na nomenclatura das disciplinas, contudo o brinquedo cantado foi um dos menos assinalados. Houve significância apenas no tema ritmo em relação ao gênero dos alunos. 
Tabela 2: Conteúdos desenvolvidos nas disciplinas de rítmica e/ou dança nas IES

\begin{tabular}{|c|c|c|c|c|c|c|c|}
\hline \multirow{2}{*}{$\begin{array}{l}\text { Conteúdos } \\
\text { Alongamento }\end{array}$} & \multicolumn{2}{|c|}{ Feminino } & \multicolumn{2}{|c|}{ Masculino } & \multicolumn{2}{|c|}{ Total } & \multirow[t]{2}{*}{ Valordep } \\
\hline & $\mathrm{N}$ & $\%$ & $\mathrm{n}$ & $\%$ & $\mathrm{~N}$ & $\%$ & \\
\hline Sim & 170 & 80,2 & 134 & 76,6 & 304 & 78,6 & 0,388 \\
\hline Não & 42 & 19,8 & 41 & 23,4 & 83 & 21,4 & \\
\hline \multicolumn{8}{|c|}{ Brinquedo Cantado } \\
\hline Sim & 96 & 45,3 & 80 & 45,7 & 176 & 45,4 & 0,932 \\
\hline Não & 116 & 54,7 & 95 & 54,3 & 211 & 54,5 & \\
\hline \multicolumn{8}{|c|}{ Comp. Coreográfica } \\
\hline Sim & 174 & 82,1 & 134 & 76,6 & 308 & 79,6 & 0,181 \\
\hline \multirow{2}{*}{\multicolumn{8}{|c|}{ Consciência Corporal }} \\
\hline & & & & & & & \\
\hline Sim & 130 & 61,3 & 100 & 57,1 & 230 & 59,4 & 0,405 \\
\hline Não & 82 & 38,7 & 75 & 42,9 & 157 & 40,6 & \\
\hline \multicolumn{8}{|l|}{ Dança } \\
\hline Sim & 179 & 84,4 & 143 & 81,7 & 322 & 832 & 0,476 \\
\hline \multirow{2}{*}{\multicolumn{8}{|c|}{ Dança Folclórica }} \\
\hline & & & & & & & \\
\hline Sim & 152 & 71,7 & 116 & 66,3 & 268 & 693 & 0,251 \\
\hline Não & 60 & 28,3 & 59 & 33,7 & 119 & 30,7 & \\
\hline \multicolumn{8}{|c|}{ Expressão Corporal } \\
\hline Sim & 156 & 73,6 & 128 & 73,1 & 284 & 73,4 & 0,922 \\
\hline Não & 56 & 26,4 & 47 & 26,9 & 103 & 26,6 & \\
\hline \multicolumn{8}{|c|}{ Atividades Rítmicas } \\
\hline Sim & 149 & 70,3 & 135 & 77,1 & 284 & 73,4 & 0,129 \\
\hline Não & 63 & 29,7 & 40 & 22,9 & 103 & 26,6 & \\
\hline \multicolumn{8}{|l|}{ Movimento } \\
\hline Sim & 184 & 86,8 & 141 & 80,6 & 325 & 84,0 & 0,097 \\
\hline Não & 28 & 13,2 & 34 & 19,4 & 62 & 16,0 & \\
\hline \multicolumn{8}{|l|}{ Musical } \\
\hline Sim & 166 & 78,3 & 129 & 73,7 & 295 & 762 & 0,291 \\
\hline Não & 46 & 21,7 & 46 & 26,3 & 92 & 23,8 & \\
\hline \multicolumn{8}{|l|}{ Ritmo } \\
\hline Sim & 133 & 86,3 & 135 & 77,1 & 318 & 822 & $0,019^{*}$ \\
\hline Não & 29 & 13,7 & 40 & 22,9 & 69 & 17,8 & \\
\hline
\end{tabular}

Comp. Coreográfica - Composição Coreográfica; *significativo a 95\%.

Também foram propostas questões sobre a aplicabilidade do tema no mercado de trabalho (tabela 4). A maioria dos alunos afirmou que utiliza ou utilizaria o conteúdo de atividades rítmicas em suas aulas de $\mathrm{EF}(\mathrm{p}=0,036)$ como tema complementar, o que se torna um ponto positivo para o tema rítmica/dança já que os alunos parecem ter entendido o significado dessa disciplina, que é o de oferecer possibilidades e conhecimento e não formar bailarinos. Parte dos alunos respondeu não utilizar a disciplina em suas aulas por dois motivos principais: não acharem ter experiência suficiente para trabalhar este tema em aula, e não considerarem este tema de grande importância para as aulas. Quando questionados se utilizariam a referida disciplina em atividades 
esportivas, a maioria respondeu negativamente $(\mathrm{p}=0,001)$, com a mesma justificativa anterior.

Tabela 3: Aplicabilidade dos conteúdos abordados segundo suas ementas no mercado de trabalho

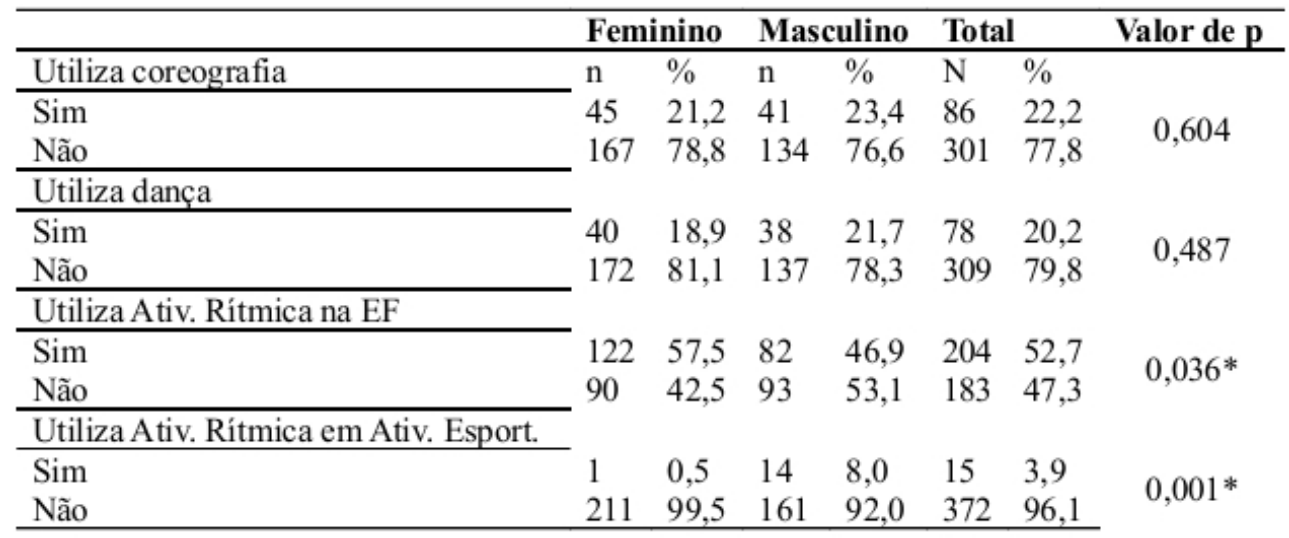

Ativ. Rítmica - Atividades Rítmicas; Ativ. Esport. - Atividades Esportivas *significativo a $95 \%$.

$\mathrm{Na}$ tabela 5, apresentam-se palavras-chave escolhidas de acordo com as respostas dos alunos sobre os pontos positivos e pontos negativos da disciplina. Os principais pontos positivos foram em relação à habilidade motora, percepção em relação ao ritmo e a dança, e a contribuição para as aulas de EF. Entre os pontos negativos citados os mais relevantes foram a falta de didática do professor que caracteriza o descaso destes com o processo de formação continuada, além do desinteresse por parte dos alunos. Porém, esses dados não foram significativos.

Tabela 4: Pontos positivos e negativos da disciplina na visão dos alunos das IES

\begin{tabular}{llllllll}
\hline & \multicolumn{2}{l}{ Feminino } & \multicolumn{2}{l}{ Masculino } & \multicolumn{2}{c}{ Total } & Valor de p \\
\hline Pontos Positivos & $\mathrm{N}$ & $\%$ & $\mathrm{~N}$ & $\%$ & $\mathrm{~N}$ & $\%$ & \\
\hline Habilidade motora & 109 & 51,4 & 89 & 50,9 & 198 & 51,2 & 0,913 \\
\hline Percepção do ritmo/dança & 82 & 38,7 & 73 & 41,7 & 155 & 40,1 & 0,544 \\
\hline Aulas de EF & 72 & 34,0 & 54 & 30,9 & 126 & 32,6 & 0,516 \\
\hline Desinibição & 25 & 11,8 & 23 & 13,1 & 48 & 12,4 & 0,688 \\
\hline Musicalidade & 19 & 9,0 & 8 & 4,6 & 27 & 7,0 & 0,091 \\
\hline Folclore/Cultura & 12 & 5,7 & 10 & 5,7 & 22 & 5,7 & 0,982 \\
\hline Pontos Negativos & $\mathrm{N}$ & $\%$ & $\mathrm{~N}$ & $\%$ & $\mathrm{~N}$ & $\%$ & \\
\hline Falta de didática do Professor & 31 & 14,6 & 16 & 9,1 & 47 & 12,1 & 0,100 \\
\hline Desinteresse & 26 & 12,3 & 20 & 11,4 & 46 & 11,9 & 0,800 \\
\hline Não relacionado à escola & 13 & 6,1 & 12 & 6,9 & 25 & 6,5 & 0,773 \\
\hline Espaço e materiais inadequados & 6 & 2,1 & 9 & 5,1 & 15 & 3,9 & 0,241 \\
\hline Conteúdos superficiais & 4 & 1,9 & 4 & 2,3 & 8 & 2,1 & 0,784 \\
\hline Falta musicalidade & 3 & 1,4 & 0 & 0,0 & 3 & 0,8 & 0,319 \\
\hline
\end{tabular}

* significativo a $95 \%$. 
Quando os alunos foram solicitados a apontar melhorias quanto à disciplina, 5,9\% sugeriram maior enfoque na formação profissional, mostrando que apesar de estarem desinteressados nas aulas, entendem o seu papel como futuros profissionais da EF, trabalhando com a educação corporal, cognitiva e intelectual. Sugeriram também mais fundamentos teóricos $(4,4 \%)$, maior aprofundamento no tema dança $(11,9 \%)$, maior carga horária para a disciplina (16,8\%) e observação, como visitas em academias, apresentações de dança entre outras atividades $(1,9 \%)$.

\section{Discussão}

De acordo com os objetivos traçados para esse estudo, sendo o principal investigar a disciplina de rítmica e/ou dança nos cursos de EF do Estado de Santa Catarina na percepção dos alunos, pode-se ressaltar que as ementas das disciplinas diferem nas nomenclaturas usadas de uma IES para outra, apesar das mesmas serem semelhantes. As ementas devem conter conteúdos representativos dos elementos centrais de conhecimentos e habilidades a serem desenvolvidos (NUNES; NORONHA \& AMBIEL, 2007). A partir desse conceito, vê-se que as disciplinas de dança e/ou rítmica devem fazer parte do currículo, pois oferecem subsídios para a formação do futuro profissional, entre eles fundamentos para enriquecer o processo de comunicação de indivíduos, além de poder ser utilizado como instrumento didático para facilitar a assimilação na aprendizagem do movimento (SOUZA JR., 2002).

Desta forma, constatou-se que a maioria das ementas contém a dança em suas disciplinas, envolvendo sua história, seus estilos, tipos de movimentação, deslocamentos e técnicas como tema em comum e sendo mais utilizado, de acordo com conceito expressado anteriormente. Percebe-se também que o tema dança educação, que envolve a dança na escola, a prática pedagógica, os planos de aula e a dança interdisciplinar foram igualmente contemplados. Já o tema coreografia está presente nas ementas englobando conteúdo de pesquisa, elaboração e montagem coreográfica. Todavia, o tema atividades rítmicas foi o menos citado, mesmo tendo boa parte das disciplinas apresentado esse título em sua nomenclatura, deixando desta forma uma lacuna no desenvolvimento prático da disciplina.

Os temas citados nas ementas/disciplinas devem trazer ao futuro professor a contextualização da dança como expressão corporal, com 
sentidos e significado (EHREMBERG, 2003). A estrutura curricular sem a presença da disciplina contribui para a manutenção de um ciclo vicioso, pois os jovens que ao entrarem no curso e não passarem por vivências específicas em ritmo tornar-se-ão profissionais sem o conhecimento básico que é solicitado em diversas oportunidades nas disciplinas de atuação (Souza Jr., 2002). Reforçando os nossos resultados, um estudo realizado pelo mesmo autor no curso da Faculdade Integrada de Guarulhos, ressaltou que os alunos destacaram a relevância da disciplina para a formação profissional e desenvolvimento pessoal, porém, um pequeno número de alunos assinalou a disciplina como irrelevante, talvez pelo fato de não terem visualizado sua importância na prática. Tal ocorrência para alguns autores como Pellegrine (1988), Verenguer (1997), Araújo et al. (2006) pode ser elucidado em função de a formação do profissional ser dada em pinceladas superficiais deste conteúdo e muitas vezes não apresentar sua aplicabilidade e importância quando os mesmos forem atuar no mercado de trabalho.

Em nosso estudo, os alunos, assim como Betti \& Betti (1996), apostam na relação entre teoria e prática. Tais autores explicam a prática como sendo a aplicação e a integração dos conhecimentos teóricos; tanto que para os alunos, com essa metodologia, o que é aprendido, é assimilado, e fica mais fácil sua aplicação. Todavia, Ghilardi (1998) acredita que a teoria refere-se aos conhecimentos produzidos e a prática à aplicação destes conhecimentos, sendo que a importância desta relação está na necessidade de uma atuação profissional fundamentada em conhecimentos científicos que vão justificar suas atitudes diante da pessoa a qual prestaram serviços. Desta forma, é possível entender o porquê em algumas instituições em que a teoria é desvinculada da prática, o aluno passe a não identificar a disciplina como tendo tanta importância.

A maioria dos alunos deste estudo ainda ressalta a importância dos assuntos tratados na disciplina de rítmica e/ou dança, tanto que tal maioria percebeu um desenvolvimento profissional, que não se restringe à memorização de conteúdo, e sim a assimilação deste. Estudiosos ressaltam que as aulas ministradas que envolvem teoria, prática e criação, proporcionam ao aluno discussão de resultados e conclusões de aula, sendo o professor o mediador da informação, proporcionando condições para que o aluno assimile o máximo do que será apresentado e ainda reflita e construa sua auto-organização (SOUZA Jr., 2002). O objetivo da Educação Física para com esta disciplina não é a de for- 
mar atletas ou bailarinos, e sim oferecer um leque de possibilidades corporais e conhecimentos a partir de assuntos diferenciados, não apenas ligados à coreografia, mas também com o objetivo de ensinar (PEREIRA \& HUNGER, 2006).

Os conteúdos relacionados ao movimento, seguido pelo tema dança e ritmo, são os mais trabalhados pelos professores das disciplinas, assim como mostra este estudo. Ao se trabalhar com o movimento, consequentemente está se aprimorando o ritmo que será utilizado em outras disciplinas, tais como: basquetebol, voleibol, natação etc; pois de acordo com Retondar (2001) a competência rítmica auxilia os alunos a conhecer melhor seu mundo, os objetos, o mundo dos outros e a realidade a qual pertence. Além disso, as atividades rítmicas estimulam a coordenação, o desenvolvimento das habilidades motoras, auxilia na concentração, na atenção, na postura, na percepção auditiva, visual e corporal, despertando a criatividade e a expressão do corpo (QUEIRÓS, 2003; MULLER \& TAFNER 2007; BORGES; SOUZA \& PEREIRA, 2008). Tanto que para Santos (2003) a falta do desenvolvimento deste tema interfere de forma significativa no desenvolvimento psicomotor das crianças, que a partir de sua emoção são estimuladas em sua afetividade, apropriando-se do uso desses elementos lúdicos sonoros para investimento pessoal e social, além de aflorar a criatividade, a expressividade do corpo e da alma revelando as habilidades e dificuldades do aluno.

Neste estudo a maioria dos alunos afirma que utilizaria o conteúdo de atividades rítmicas em suas aulas de EF como tema complementar, o que é bem positivo, pois mostra que estes entenderam que a função do professor não é formar bailarinos e/ou atletas, mas sim propiciar o aprendizado para o ensino nas escolas. Entretanto, alguns alunos ainda sentem-se inseguros, pois consideram a disciplina muito peculiar; sentem-se em certos momentos constrangidos em algumas atividades, principalmente homens, e ainda acreditam que o aprendizado é insuficiente dentro das IES para ministrarem aulas desta disciplina enquanto profissionais de EF. Além disso, preocupa-se que as atividades aprendidas não são do interesse dos alunos (homens) fora das IES, corroborando com os achados de Gomes Jr. e Lima (2003).

Entretanto, outros alunos acham importante utilizar o tema em aula para maior integração dos alunos, o que segundo os autores se apresenta como um caminho de inversão da sociedade individualizada manifestada no corpo. Para Miranda (1991), este fato está presente pela 
indefinição do objetivo da dança para o profissional de EF e por este tema ser insuficiente para denominar-se "formação em dança". Podese, então, considerar que alguns alunos pensam a dança em seu curso como um tema a ser trabalhado, apenas por aqueles que possuem experiências anteriores à vida acadêmica, excluindo as outras possibilidades de trabalho, como os papéis sociais e de conhecimento significativo para as ações corpóreas, que pode ser explorado pelo universo de repertórios popular e folclórico, assim como pela improvisação (BRASILEIRO, 2002; MIRANDA, 1991).

Outro assunto abordado com os alunos se refere ao espaço físico, o qual se configura em um fator motivacional na realização das aulas, sendo bem apreciado pelos alunos nesse estudo. Porém, para Brasileiro (2003), no mercado de trabalho não será este o contexto encontrado pelos futuros profissionais; ele relata não haver espaço físico, ou os mesmos são inadequados e dificultam a atuação do profissional, diferentemente daqueles encontrados nas IES. O que gera preocupação, uma vez que estes já possuem certo preconceito e medo de trabalhar o tema em suas aulas este é um fator predisponente a não utilização do mesmo.

Com todos os pormenores aqui discutidos e revelados pelos alunos, os futuros profissionais necessitam buscar a mediação na informação, a fim de desenvolver as atividades por meio de várias dinâmicas, permitindo aos seus futuros alunos aprenderem com prazer e assim explorar sua criatividade, espontaneidade e os seus limites, despertando ainda o interesse em seus respectivos desenvolvimentos, seja pela percepção corporal ou em suas habilidades motoras (SOUZA JR., 2002). Também se faz necessário que as IES revisem suas ementas para proporcionar aos alunos um melhor aproveitamento e aplicabilidade da mesma no mercado de trabalho; visto que os alunos ressaltam como pontos positivos a habilidade motora, a percepção em relação ao ritmo e a dança, e a contribuição para as aulas de EF. Entretanto, estes têm como pontos negativos, por vezes, a falta de didática dos professores, que caracteriza o descaso destes com o processo de formação continuada, aumentando o desinteresse dos alunos, gerando certo comodismo perante a turma e ao conteúdo.

A escassez de estudos na área acabou limitando uma maior discussão do assunto, para talvez apontar caminhos e possíveis soluções que pudessem dar ao aluno uma visão mais positiva em termos de aprendizado nesta disciplina em específico, e ainda motivar e dar a ele segu- 
rança para incluir este tema em suas aulas. Dificuldades se apresentaram também nas coletas dos dados, pois a amostra envolvida encontrava-se por todo Estado de Santa Catarina, não sendo possível estar presente em todas as instituições, além do difícil acesso a alguns coordenadores de curso, da recusa em participar do estudo por parte de algumas instituições, da demora em desenvolver e aplicar os questionários, e da negação de alguns alunos em responder os mesmos.

\section{Conclusão}

Os resultados sugerem que a disciplina de rítmica e dança tem um objetivo bem definido, de não formar bailarinos e sim professores, capazes de atuar na EF escolar com rítmica e/ou dança. Na escola, os professores possuem dificuldade em desenvolver os conteúdos de dança; afirmam ter pouca experiência e também a existência de preconceito de professores do sexo masculino. Frente o exposto, os professores devem sempre buscar novos conhecimentos e enfrentar desafios, para que suas respectivas atuações não se tornem estanques e descontextualizadas, mesmo ocorrendo desmotivação por parte dos alunos. Deve-se também reconhecer a questão cultural desta divisão de gêneros de forma a confrontá-la com vistas à promoção deste conteúdo, haja vista ser o mesmo tão importante quanto os demais, para a formação de crianças e adultos. Nas instituições, podem divergir a forma como é conduzida a disciplina e também as ementas utilizadas por cada uma delas. Faz-se necessário valorizar, tanto o gênero feminino quanto o masculino, enfatizando não apenas a dança, mas o movimento, o ritmo, a expressão corporal, o brinquedo cantado, pois todos estes conteúdos fazem parte da disciplina de rítmica e dança.

Acredita-se que novas investigações, no campo da dança e rítmica, devem ser realizadas, principalmente concernente à atuação; ou seja, são necessárias outras pesquisas diretamente nas escolas com os professores atuantes, assim como com os alunos que recebem o conteúdo naquele contexto, a fim de perceber se o mesmo está sendo bem ministrado e assimilado pelos alunos; ou até mesmo como um processo de feedback entre as IES e as escolas. 


\title{
Dance and rhythmic in physical education undergraduate curricula
}

\begin{abstract}
Aim: This study investigated the dance and/or rhythmic courses in Physical Education undergraduate schools in Santa Catarina, on students' perspective. Methodology: A random stratified probabilistic sample with 387 students. Results: The most expressive statistical results are related to the importance of the course $(\mathrm{p}=0,001)$, the studied subjects $(p=0,047)$, the course in undergraduate classes $(p=0,001)$, the subject 'rhythm' developed in dance and/or rhythmic courses $(\mathrm{p}=0,019)$, the use of rhythmic activity in classes $(p=0,036)$, and sport training $(p=0,001)$. Conclusion: The course has a well defined objective of not preparing dancers, but, to prepare teachers to work with PE, in rhythmic and dance, in schools.
\end{abstract}

Keywords: Dance. Physical Activity. Rhythm.

Danza ritimica en los currículos de los cursos de educación física

\section{Resumen}

Objetivo: Este estudio investigó la asignatura rítmica y/o la danza en los cursos de la educación física en Santa Catarina en la opinión de los pupilos. Metodología: Muestra del tipo probabilístico aleatorio estratificada con 387 pupilos. Resultados: Los resultados estadísticos significativos son la importancia de la disciplina $(\mathrm{p}=0,001)$, los temas abordados $(\mathrm{p}=0,047)$, la disciplina en las lecciones de la educación física $(\mathrm{p}=0,001)$, el contenido ritmo desarrollado en la disciplina de rítmica $\mathrm{y} / \mathrm{o}$ danza $(\mathrm{p}=0,019)$, el uso de la actividad rítmica en las lecciones de educación física $(p=0,036)$ y el entrenamiento deportivo $(p=0,001)$. Conclusión: La asignatura no tiene lo objetivo de formar a los bailarines, pero, a los profesores capaces de actuar en la educación física de la escuela en rítmica y/o danza.

Palabras clave: Danza. Actividad Física. Ritmo.

\section{Referências}

ARAÚJO, M. B. et al. O ponto de vista de estudantes de Educação Física sobre os conhecimentos relevantes em situações-problema da intervenção profissional. Revista Digital, Buenos Aires, ano 11, n. 95, 2006. Disponível em: <www.efdeportes.com>. Acesso em: 11 mai. 2009.

BARBETTA, P. A. Estatística Aplicada às Ciências Sociais. 5. ed. Florianópolis: Editora da UFSC, 2004.

BARROS, M. V. G.; REIS, R. S. Análise de dados em atividade física e saúde: demonstrando a utilização do SPSS. Londrina: Midiograf, 2003. 
BETTI, M. Educação e Sociedade. São Paulo: Movimento, 1991.

BETTI, I. C. R; BETTI, M. Novas perspectivas na formação profissional em educação física. Revista Motriz, v. 2, n. 1, p. 10-15, 1996.

BORGES, T. S.; SOUZA, V. F. M.; PEREIRA, V. R. Educação Física infantil e desenvolvimento do ritmo motor na infância. Revista Digital, Buenos Aires, ano 13, n. 123, 2008. Disponível em: <www.efdeportes.com>. Acesso em: 11 mai. 2009.

BRACHT, V. As ciências do esporte no Brasil: uma avaliação critica. In: FERREIRA NETO, A.; GOELLNET, S.; BRACHT, V. (Orgs) As ciências do esporte no Brasil, Campinas, p. 29-29, 2005.

BRASIL. Ministério da Educação. Secretaria de Educação Básica. Parâmetros curriculares nacionais: Educação Física. MEC/SEF - DF, 1997.

BRASILEIRO, L. T. O conhecimento no currículo escolar: o conteúdo dança em aulas de educação física na perspectiva crítica. Movimento, Porto Alegre, v. 8, n. 3, p. 05-18, 2002.

BRASILEIRO, L. T. O Conteúdo "Dança" em aulas de Educação Física: Temos o que Ensinar. Pensar a Prática, Goiânia, v. 6, 2003.

CAUDURU, V. R. Declamando, ritmando e movimentando-se: música e ritmo são recursos educativos. Revista do Professor, Porto Alegre, ano 5, n. 20, 1989.

DAOLIO, J. Educação Física escolar, em busca da pluralidade. Revista Paulista de Educação Física, São Paulo, supl. 2, p. 40-42, 1996.

EHRENBERG, M. C. A dança como conhecimento a ser tratado pela Educação Física Escolar: aproximação entre formação e atuação profissional. 2003. Dissertação (Mestrado) - Faculdade de Educação Física, Universidade Estadual de Campinas, São Paulo, 2003.

GHILARDI, R. Formação profissional em educação física: a relação teoria e prática. Revista Motriz, v. 4, n. 1, p. 1-11, 1998. 
GOMES JR, L. M.; LIMA, L. M. Educação estética e educação física: a dança na formação de professores. Pensar a Prática, Goiânia, v. 6, p. 31-44, 2003.

GONÇALVES, A. S.; AZEVEDO, A. A. O corpo na contemporaneidade: a Educação Física escolar pode ressignificá-lo? Revista da Educação Física/UEM, Maringá, v.19, n. 1, p. 119-130, 2008.

MELO, S. I. L. Construção e Validação de Instrumento de Medida. (Unpublished) Caderno Técnico. CEFID-UDESC, 2000.

MIRANDA, M. L. J. A dança como conteúdo específico nos cursos de Educação Física e como área de estudo do ensino superior. 1991. Dissertação (Mestrado) - Escola de Educação Física, Universidade de São Paulo, São Paulo, 1991.

MULLER, R. E.; TAFNER, E. P. Desenvolvendo o ritmo nas aulas de educação física em crianças de 3 a 6 anos. Revista de Divulgação Técnico-Científica da ICPG, vol. 3, n. 11, 2007.

NUNES, M. F. O.; NORONHA, A. P. P.; AMBIEL, R. A. M. Conteúdos ensinados em disciplinas de orientação profissional na graduação em psicologia. Estudos e pesquisas em psicologia, UERJ, Rio de Janeiro, v. 7, n. 1, p. 127-137, 2007.

PEDRO, M. R. Conscientização e formação profissional em Educação Física: Indicantes da disciplina curricular "Conscientização Corporal". Disponível em: <www.webartigos.com>. Acesso em: 16 mai. 2009.

PELLEGRINI, A. M. A formação profissional em Educação Física. In: PASSOS, S. C. E, org. Educação Física e Esportes na Universidade. Brasília, UnB, 1988.

PEREIRA, M. L.; HUNGER D. A. C. F. Dança e Educação Física no Brasil: questões polêmicas. Revista Digital, Buenos Aires, ano 11, n. 96, 2006. Disponível em: <www.efdeportes.com>. Acesso em: 20 mai. 2009.

QUEIRÓS, I. L. B. G. Rítmica: Prática pedagógica da Educação Física. Caderno de Educação Física, v. 5, n. 9, p. 89-94, 2003. 
RETONDAR, J. J. M. A importância do ensino rítmico na escola. Perspectiva em Educação Física Escolar, p. 13-24, 2001.

SANTOS, D. G. Brinquedos cantados na psicomotricidade. Monografia (Pós-graduação) - Universidade Cândido Mendes, Rio de Janeiro, 2003.

SOUZA JR, O. D. A disciplina Rítmica no processo de formação dos alunos do curso de Educação Física. Revista Mackenzie de Educação Física, ano 1, n.1, p. 47-63, 2002.

VERENGUER, R. C. G. Dimensões profissionais e acadêmicas da Educação Física no Brasil: Uma síntese das discussões. Revista Paulista de Educação Física, São Paulo, v. 11, n. 2, p. 164-175, 1997.

Recebido em: 19/07/2011

Revisado em: 29/01/2012

Aprovado em: 03/04/2012

Endereço para correspondência

amandasoaresef@gmail.com

Zenite Machado

Universidade do Estado de Santa Catarina, Centro de Educação Física e Desportos.

Paschoal Simone 358 - Coqueiros

88080-350 - Florianopolis, SC - Brasil 